\title{
Relationship of Lower Breastfeeding Score and Problems in Infancy
}

\author{
S. Songül Yalçın and B. Bariş Kuşkonmaz ${ }^{2}$
}

\begin{abstract}
Background and Methods: We undertook a descriptive study in 2-month-old healthy infants to determine the factors that affect breastfeeding score. Mother's breastfeeding was evaluated and scored according to the World Health Organization/UNICEF B-R-E-A-S-T Feeding Observation Form.

Results: The breastfeeding score (BFS) was higher in female than male babies $(p=0.005)$. The babies with regurgitation had lower BFS than the babies without $(p=0.016)$. The BFS was lower in babies who had repeated, without cause, inconsolable crying than in those without such crying $(p<0.004)$. When the crying was problematic for the family, BFS was lower $(p=0.028)$. Babies who had another sibling with a history of colic had a lower BFS $(p=0.038)$. A low BFS was associated with short duration of night sleeping $(p=0.032)$.

Conclusions: A decreased BFS may be a risk factor or indicator for infant crying, regurgitation, and short sleeping duration. As a result, tracking the BFS and appropriate breastfeeding intervention during the newborn period may assist in decreasing the frequency of regurgitation and infant crying.
\end{abstract}

\section{Introduction}

B REASTFEEDING GIVES SIGNIFICANT health advantages to both the mother and growing child, and the World Health Organization (WHO) recommends exclusive breastfeeding for the first 6 months of life, with the gradual introduction of complementary foods and continuation of breastfeeding until 2 years or beyond. ${ }^{1-3}$ The promotion of successful breastfeeding has long been a major focus for healthcare providers and researchers. ${ }^{3-6}$ Using a "breastfeeding score (BFS) checklist" may help health personnel to assess breastfeeding more accurately, to identify mothers with low breastfeeding confidence who are at high risk to prematurely discontinue breastfeeding, and to determine which aspects need improving. $^{3-6}$ Then, UNICEF/WHO Baby Friendly Hospital Initiative training, including how to breastfed, can be applied to these mothers. ${ }^{3,7}$

There are several published breastfeeding assessment tools. $3,5,6,8,9$ They focus on different aspects of baby and maternal behaviors during breastfeeding interactions, such as the absence of breastfeeding problems, maternal satisfaction, and duration of the feeding. They evaluate breastfeeding according to the baby's behavior, the mother's behavior, positioning, attachment, effective feeding, health of the breast, health of the baby, and mother's experience.

Successful breastfeeding is influenced by maternal characteristics and social situation. ${ }^{2-4,10}$ Therefore, some factors, including delivery type, parity, gestational age, birth weight of infant, and lactation consultants, might have a role influencing the BFS.,11 Determining the factors that affect BFS might improve child breastfeeding. Some mothers complain about sleeping, regurgitation, and crying problems of their infants, and, to the best of our knowledge, there has been no published study to date on breastfeeding patterns of infants with such problems. Considering the lack of data, we undertook a descriptive study in 2-month-old infants to determine the effect of maternal and infant characteristics on BFS by using the WHO/UNICEF B-R-E-A-S-T-Feeding Observation Form and to evaluate the BFS of infants demonstrating regurgitation, crying, and sleeping problems.

\section{Subjects and Methods}

This descriptive study was conducted at the Unit of Social Pediatrics, Department of Pediatrics, Hacettepe University Faculty of Medicine, Ankara, Turkey. Only healthy infants (2 months of age) were included in the study; infants hospitalized for any reason and infants with acute or chronic disease were excluded. Infants with vomiting, which denotes an active reflux process or with pathologic regurgitation (regurgitating more than $20 \mathrm{~mL} /$ day or any complication of gastroesophageal reflux, including failure to thrive or pulmonary disease) were not accepted for this study. To prevent the effect of previous breastfeeding counseling on BFS, the

Units of ${ }^{1}$ Social Pediatrics and ${ }^{2}$ Hematology, Department of Pediatrics, Hacettepe University Faculty of Medicine, Ankara, Turkey. 
Table 1. General Characteristics of the Study Population $(N=82)$

\begin{tabular}{|c|c|}
\hline Demographic & Value \\
\hline Gestational age (weeks) & $38.9 \pm 1.7$ \\
\hline Maternal age (years) & $30.2 \pm 4.7$ \\
\hline $\begin{array}{l}\text { Educational level of the mother } \\
>8 \text { years }\end{array}$ & $68(82.9 \%)$ \\
\hline $\begin{array}{l}\text { Prenatal and/or postnatal } \\
\text { maternal smoking }\end{array}$ & $11(13.4 \%)$ \\
\hline Paternal smoking & $41(50.0 \%)$ \\
\hline $\begin{array}{l}\text { Mode of delivery (spontaneous } \\
\text { vaginal/cesarean) }\end{array}$ & $35 / 47$ \\
\hline Birth weight $(\mathrm{g})$ & $3197 \pm 461$ \\
\hline Male/female baby & $42 / 40$ \\
\hline $\begin{array}{l}\text { Repeated, inconsolable crying } \\
\text { without apparent cause }\end{array}$ & $55(67.1 \%)$ \\
\hline Problematic crying for the family & $14(17.1 \%)$ \\
\hline Daily crying duration $\geq 60$ minutes & $12(14.6 \%)$ \\
\hline Consultation to a doctor for colic & $13(15.9 \%)$ \\
\hline $\begin{array}{l}\text { Infants with complaint of daily } \\
\text { regurgitation }\end{array}$ & $51(62.2 \%)$ \\
\hline Infants with constipation & $13(15.9 \%)$ \\
\hline Bottle usage & $28(34.1 \%)$ \\
\hline Pacifier usage & $37(45.1 \%)$ \\
\hline $\begin{array}{l}\text { Presence of primary caregiver } \\
\text { other than the mother }\end{array}$ & $14(17.1 \%)$ \\
\hline $\begin{array}{l}\text { First breastfeeding time } \geq 2 \text { hours } \\
\text { after delivery }\end{array}$ & $30 / 82(36.6 \%)$ \\
\hline Daily frequency of breastfeeding & $10.47 \pm 3.78$ \\
\hline $\begin{array}{l}\text { Frequency of breastfeeding } \\
\text { at night (21:00-07:00 hours) }\end{array}$ & $2.74 \pm 1.30$ \\
\hline \multicolumn{2}{|l|}{ Duration of } \\
\hline Breastfeeding (minutes) & $17.5 \pm 11.5$ \\
\hline $\begin{array}{l}\text { Sleeping during the day } \\
\text { (08:00-20:00 hours) (hours) }\end{array}$ & $6.1 \pm 2.3$ \\
\hline $\begin{array}{l}\text { Sleeping at night } \\
\text { (21:00-07:00 hours) (hours) }\end{array}$ & $6.7 \pm 1.9$ \\
\hline
\end{tabular}

Data are mean \pm SD values or $n(\%)$ as indicated.

mothers who had received breastfeeding counseling on admission were excluded from this study. All suitable infants and mothers with verbal consent were included in the study.

During the 2-month study period, a total of 217 motherinfant pairs were admitted to our unit; 125 mothers and their babies were excluded from the study because of history of receiving breastfeeding counseling, and four of them were excluded because of hospitalization and acute or chronic disease. Among the remaining 88 mothers, 82 of them who gave verbal consent were included in the study.

A questionnaire including gestational age, sex, birth weight, type of delivery, maternal/paternal smoking, infant's crying characteristics, regurgitation, constipation, bottle/pacifier usage, presence of a primary caregiver other than the mother, educational level of the mother, time of the first breastfeeding, frequency and duration of breastfeeding, and infant sleeping duration was given to mothers. There were four generally formulated questions regarding parental concern about crying and colic: namely, about whether mothers thought their infants sometimes had repeated, inconsolable crying, without apparent cause; whether the infant's crying constituted a problem for her or the rest of the family; whether they considered that the daily duration of crying was $\geq 60$ minutes; and whether mothers felt the need to seek help from a doctor. ${ }^{12,13}$

In an otherwise healthy infant, regurgitation was defined to the mothers as the effortless return of gastric contents at least into the mouth. ${ }^{14}$ Infants who regurgitate at least once a day were defined as a regurgitating infant.

The breastfeeding technique of the mother was evaluated and scored according to the B-R-E-A-S-T Feeding Observation Form, ${ }^{3}$ which is a tool developed for use by health professionals carrying out the WHO/UNICEF Breastfeeding Management course. This Form is divided into six sections: body position, responses, emotional bonding, anatomy, suckling, and time spent suckling. The Form consists of two columns: one indicating signs of a successful breastfeeding, and the other giving the opposing signs. If the health worker records only positive signs, this indicates that breastfeeding is probably going well. If some negative signs are observed, this indicates that there may be problems, and follow-up action may be required. Positive signs were coded as 1 , and all positive signs were summed. There were 25 items, and each positive item was multiplied by 4 . In this manner, a mother-infant pair with only positive signs had 100 for a BFS. Sucking period was not taken into consideration.

Table 2. Breastfeeding Score According to Infant Parameters $(N=82)$

\begin{tabular}{|c|c|c|c|}
\hline Parameter & $\mathrm{n}$ & $\begin{array}{l}\text { Breastfeeding } \\
\text { score }\end{array}$ & $\mathrm{p}$ \\
\hline Sex & & & 0.005 \\
\hline Male & 42 & $83.7 \pm 7.4$ & \\
\hline Female & 40 & $88.8 \pm 8.8$ & \\
\hline Delivery mode & & & 0.354 \\
\hline Vaginal & 35 & $87.2 \pm 9.3$ & \\
\hline Cesarean & 47 & $85.5 \pm 7.7$ & \\
\hline First food given to the infant & & & 0.852 \\
\hline Breastfeeding & 68 & $86.1 \pm 8.5$ & \\
\hline Infant formula & 14 & $86.6 \pm 8.1$ & \\
\hline Bottle usage & & & 0.712 \\
\hline Yes & 28 & $85.7 \pm 7.5$ & \\
\hline No & 54 & $86.4 \pm 8.9$ & \\
\hline Pacifier usage & & & 0.730 \\
\hline Yes & 37 & $85.8 \pm 8.3$ & \\
\hline No & 45 & $86.5 \pm 8.6$ & \\
\hline Presence of daily regurgitation & & & 0.016 \\
\hline Yes & 51 & $84.5 \pm 8.2$ & \\
\hline No & 31 & $89.0 \pm 8.2$ & \\
\hline Constipation & & & 0.245 \\
\hline Yes & 13 & $83.7 \pm 8.6$ & \\
\hline No & 69 & $86.7 \pm 8.4$ & \\
\hline Color of the stool & & & 0.796 \\
\hline Yellow & 54 & $86.4 \pm 8.4$ & \\
\hline Green-yellow/green & 28 & $85.9 \pm 8.5$ & \\
\hline Stool consistency & & & 0.702 \\
\hline Watery & 34 & $85.8 \pm 8.8$ & \\
\hline Solid (firm) & 48 & $86.5 \pm 8.2$ & \\
\hline $\begin{array}{l}\text { Presence of caregiver other } \\
\text { than the mother }\end{array}$ & & & 0.610 \\
\hline Yes & 14 & $85.1 \pm 7.8$ & \\
\hline No & 68 & $86.4 \pm 8.6$ & \\
\hline
\end{tabular}

Breastfeeding score data are mean \pm SD values. 


\section{Statistical analysis}

Data were analyzed using SPSS version 10.0 for Windows software (SPSS Inc., Chicago, IL). Results were reported as mean \pm SD values or $n(\%)$ where appropriate. The normality of data distribution was checked using the KolmogorovSmirnov test in the whole group and the subgroups. Student's $t$ test was used to compare BFS in groups with normal distribution, whereas the Mann-Whitney $U$ test was used in groups with skewed distribution. Pearson correlation coefficients were calculated. A $p$ value of $<0.05$ was considered to indicate statistical significance.

\section{Results}

General characteristics of enrolled cases are given in Table 1. Of the 82 babies, 42 were male, and 40 were female.

Mean $( \pm \mathrm{SD})$ BFS was $86.2( \pm 8.4)$. The BFS was higher in female than male babies ( $88.8 \pm 8.8$ vs. $83.7 \pm 7.4$, respectively; $p=0.005$ ) (Table 2). The babies with regurgitation had lower BFS than the babies without $(84.5 \pm 8.2$ vs. $89.0 \pm 8.2$, respectively; $p=0.016$ ) (Table 2). The BFS was lower in babies who had repeated, inconsolable crying without cause than in those without such crying $(84.4 \pm 7.7$ vs. $89.9 \pm 8.8$, respectively; $p=0.004$ ) (Table 3$)$. When the crying was problematic for the family, BFS was lower $(81.7 \pm 6.2$ vs. $87.1 \pm 8.5 ; p=0.028)$ (Table 3). The babies who had another sibling with a history of colic had a lower BFS than those without such a sibling history $(83.5 \pm 8.7$ vs. $88.7 \pm 7.8 ; p=0.038)$. Low BFS was associated with short duration of sleeping between 21:00 and 07:00 hours $(r=0.238, p=0.032)$. There was no correlation between BFS and birth weight, gestational age, time of the first breastfeeding, frequency of breastfeeding, and duration of breastfeeding. Presence of infant's constipation, first food given to infant, and bottle or pacifier usage did not significantly affect BFS.

TAble 3. Breastfeeding Score According to Infant Crying Characteristics $(N=82)$

\begin{tabular}{lccc}
\hline & & $\begin{array}{c}\text { Breastfeeding } \\
\text { score }\end{array}$ & $\mathrm{p}$ \\
Parameter & $\mathrm{n}$ & & 0.004 \\
\hline $\begin{array}{l}\text { Repeated, inconsolable crying } \\
\quad \text { without apparent cause }\end{array}$ & & & \\
$\quad$ Yes & 55 & $84.37 \pm 7.7$ & \\
$\quad$ No & 27 & $89.93 \pm 8.8$ & \\
Crying problematic for the & & & 0.028 \\
$\quad$ family & 14 & $81.71 \pm 6.2$ & \\
$\quad$ Yes & 68 & $87.12 \pm 8.5$ & \\
$\quad$ No & & & 0.597 \\
$\begin{array}{l}\text { Daily duration of crying } \\
\quad(\geq 60 \text { minutes) }\end{array}$ & 12 & $85.00 \pm 7.5$ & \\
$\quad$ Yes & 70 & $86.40 \pm 8.6$ & \\
$\quad$ No & & & 0.059 \\
Consultation to a doctor & & & \\
$\quad$ for colic & 13 & $82.15 \pm 8.9$ & \\
$\quad$ Yes & 69 & $86.96 \pm 8.2$ & \\
$\quad$ No & & & 0.038 \\
Sibling with colic history & & & \\
$\quad(n=45)$ & $22 / 45$ & $83.46 \pm 8.7$ & \\
$\quad$ Yes & & & \\
$\quad$ No & $23 / 45$ & $88.70 \pm 7.8$ & \\
\hline
\end{tabular}

Breastfeeding score data are mean \pm SD values.
Maternal factors, including age, education, active or passive smoking exposure, type of delivery, and presence of another caregiver other than the mother, had no significant effect on BFS (Table 2) of infants 2 months old.

\section{Discussion}

In the present study, $57.6 \%$ of mothers admitted to our center received lactation counseling. In our previous study, $68.3 \%$ of mothers received lactation counseling support. ${ }^{15}$ In a recent hospital-based study, we also found that $24 \%$ of the mothers received breastfeeding counseling during their pregnancy and $65 \%$ of the mothers did so in the hospital after labor. ${ }^{16}$ The results show that more efforts are necessary to give the lactation counseling programs to every pregnant and lactating mother.

To the best of our knowledge, there has been no previous study evaluating the impact of infant and maternal factors on the BFS. Interestingly, we found that the BFS is higher in female than male babies; it is speculated that this may stem from behavioral differences between female and male babies. Obviously, this aspect needs further evaluation.

A second notable factor was regurgitation. Uncomplicated regurgitation in otherwise healthy infants is not a disease. ${ }^{14}$ It consists of milk flow from the mouth during or after feeding. Common causes include overfeeding, air swallowed during feeding, crying, or coughing; physical exam is normal, and weight gain is adequate. Our data suggest a difference in BFS according to the presence or absence of regurgitation. Babies who regurgitate had lower BFS than those who did not. One explanation for this is that the infants with lower BFS might swallow more air during sucking then regurgitate. However, regurgitation might decrease BFS, and additional cohort studies should be done to show which one is first.

Lower BFS was also associated with crying characteristics, including repeated, inconsolable crying without cause, problematic crying for the family, and presence of a sibling with history of infantile colic. It was speculated that a lower BFS may indicate an increased risk of worse crying characteristics. We cannot, however, determine if there is a causal relation between colic and feeding problems from this study.In our previous nested case-control study, colic was found to be associated with various perinatal factors (maternal education, smoking habits, cheese consumption, hostility scores, and domestic violence). ${ }^{17}$ However, BFS was evaluated in infants with problematic crying for the first time. The present study indicates that higher BFS might decrease the colic incidence. On the other hand, it is possible that low BFS contribute to colic symptoms, that colic contributes to low BFS, or that they are co-occurring conditions with similar etiologies. As a limitation of a descriptive study, we could not say which comes first: lower BFS or crying. Previously, MillerLoncar et al. ${ }^{18}$ reported that infants in the colic group displayed more difficulties with feeding, including disorganized feeding behaviors, less rhythmic nutritive and non-nutritive sucking, more discomfort following feedings, and lower responsiveness during feeding interactions. Further studies are necessary to analyze these interactions.

The B-R-E-A-S-T Feeding Observation Form is used all over the world as a part of UNICEF/WHO Baby Friendly Hospital Initiative training. ${ }^{3}$ The most commonly reported reasons are 
that such a tool would enable healthcare workers to determine areas of needed follow-up care and to facilitate the teaching of breastfeeding techniques to both parents and health workers. In our study, it was also found that tracking the BFS and appropriate breastfeeding observation during the newborn period may decrease the occurrence of regurgitation and problematic crying. Determinants for lower BFS could be male infants, infants with regurgitation, inconsolable crying, and sleeping problems.

\section{Disclosure Statement}

No competing financial interests exist.

\section{References}

1. Gartner LM, Morton J, Lawrence RA, et al. Breastfeeding and the use of human milk. Pediatrics 2005;115:496-506.

2. World Health Organization Department of Nutrition for Health and Development. The Optimal Duration of Exclusive Breastfeeding: Report of an Expert Consultation. World Health Organization, Geneva, 2002.

3. WHO/UNICEF. Breast-Feeding Management: A Modular Course. UNICEF, London, 1997.

4. Ingram J, Johnson D, Greenwood R. Breastfeeding in Bristol: Teaching good positioning, and support from fathers and families. Midwifery 2002;18:87-101.

5. Kronborg H, Vaeth M, Olsen J, et al. Early breastfeeding cessation: Validation of a prognostic breastfeeding score. Acta Paediatr 2007;96:688-692.

6. Mercer AM, Teasley SL, Hopkinson J, et al. Evaluation of a breastfeeding assessment score in a diverse population. $J$ Hum Lact 2010;26:42-48.

7. Spiby H, McCormick F, Wallace L, et al. A systematic review of education and evidence-based practice interventions with health professionals and breast feeding counsellors on duration of breast feeding. Midwifery 2009;25:50-61.

8. Moran VH, Dinwoodie K, Bramwell R, et al. A critical analysis of the content of the tools that measure breastfeeding interaction. Midwifery 2000;16:260-268.
9. Riordan JM, Koehn M. Reliability and validity testing of three breastfeeding assessment tools. J Obstet Gynecol Neonatal Nurs 1997;26:181-187.

10. Isabella P, Isabella R. Correlates of successful breastfeeding: A study of social and personal factors. J Hum Lact 1994;10: 247-264.

11. Cakmak H, Kuguoglu S. Comparison of the breastfeeding patterns of mothers who delivered their babies per vagina and via cesarean section: An observational study using the LATCH breastfeeding charting system. Int J Nurs Stud 2007;44:1128-1137.

12. Canivet C, Jakobsson I, Hagander B. Colicky infants according to maternal reports in telephone interviews and diaries: A large Scandinavian study. J Dev Behav Pediatr 2002;23:1-8.

13. Reijneveld SA, Brugman E, Hirasing RA. Excessive infant crying: The impact of varying definitions. Pediatrics 2001;108: 893-897.

14. Hegar B, Dewanti NR, Kadim M, et al. Natural evolution of regurgitation in healthy infants. Acta Paediatr 2009;98:11891193.

15. Erkul PE, Yalçın SS, Kılıç S. Evaluation of breastfeeding in a Baby-friendly city, Corum, Turkey. Cent Eur J Public Health 2010;18:31-37.

16. Ince $\mathrm{T}$, Kondolot $\mathrm{M}$, Yalçın SS, et al. Breastfeeding consultation status of mothers [in Turkish]. Çocuk Să̆ll $\breve{g} l$ ve Hastalıkları Dergisi 2010;53:189-197.

17. Yalçın SS, Orun E, Mutlu B, et al. Why are they having infantile colic? A nested case-control study. Paediatr Perinat Epidemiol 2010;24:584-596.

18. Miller-Loncar C, Bigsby R, High $\mathrm{P}$, et al. Infant colic and feeding difficulties. Arch Dis Child 2004;89:908-912.

Address correspondence to: S. Songül Yalçın, M.D. Unit of Social Pediatrics Department of Pediatrics Hacettepe University Faculty of Medicine Samanpazari 06100, Ankara, Turkey

E-mail: siyalcin@hacettepe.edu.tr 